\title{
Cultivation of Oily Microalgae for the Production of Third-Generation Biofuels
}

\author{
Preeti Pal ${ }^{1}$, Kit Wayne Chew ${ }^{2}(0)$, Hong-Wei Yen ${ }^{3}$, Jun Wei Lim ${ }^{4}{ }^{(0)}$, Man Kee Lam ${ }^{5}$ \\ and Pau Loke Show ${ }^{6, *}$ \\ 1 School of Environmental Science and Engineering, Indian Institute of Technology, Kharagpur, \\ West Bengal 721302, India; palpreiti@gmail.com \\ 2 School of Mathematical Sciences, Faculty of Science and Engineering, University of Nottingham Malaysia, \\ Jalan Broga, Semenyih 43500, Selangor Darul Ehsan, Malaysia; kitwayne.chew@gmail.com \\ 3 Department of Chemical and Materials Engineering, Tunghai University, Taichung 002105-7, Taiwan; \\ hwyen@thu.edu.tw \\ 4 Department of Fundamental and Applied Sciences, Centre for Biofuel and Biochemical Research, \\ Institute of Self-Sustainable Building, Universiti Teknologi PETRONAS, Seri Iskandar 32610, \\ Perak Darul Ridzuan, Malaysia; junwei.lim@utp.edu.my \\ 5 Chemical Engineering Department, Universiti Teknologi PETRONAS, Seri Iskandar 32610, Perak, Malaysia; \\ lam.mankee@utp.edu.my \\ 6 Department of Chemical and Environmental Engineering, Faculty of Science and Engineering, \\ University of Nottingham Malaysia, Jalan Broga, Semenyih 43500, Selangor Darul Ehsan, Malaysia \\ * Correspondence: PauLoke.Show@nottingham.edu.my; Tel.: +60-(03)-8924-860
}

Received: 19 June 2019; Accepted: 29 August 2019; Published: 30 September 2019

\begin{abstract}
Biofuel production by oleaginous microalgae is a promising alternative to the conventional fossil fuels. Many microalgae species have been investigated and deemed as potential renewable sources for the production of biofuel, biogas, food supplements and other products. Oleaginous microalgae, named for their ability to produce oil, are reported to store $30-70 \%$ of lipid content due to its metabolic properties under nutrient starvation conditions. This review presents the assortment of the research studies focused on biofuel production from oleaginous microalgae. The new methods and technologies developed for oleaginous microalgae cultivation to improve their biomass content and lipid accumulation capacity were reviewed. The production of renewable, carbon neutral, bio-based or microalgae-based transport fuels are necessary for environmental protection and economic sustainability. Microalgae are a significant source of renewable biodiesel because of their ability to produce oils in the presence of sunlight more efficiently than that of crop oils. This review will provide the background to understanding the bottlenecks and the need for improvement in the cultivation or harvesting process for oleaginous microalgae.
\end{abstract}

Keywords: algae culture; biodiesel; bioenergy; microalgae biomass; phototrophic

\section{Introduction of Microalgae}

Microalgae are uprising feedstock that have great prospects in replacing petroleum-based fuels. The rising dependence on fossil fuels is alarming and the alternative of microalgae biofuels, which have high productivity potential and less competition with food production, is becoming increasingly popular. Microalgae contain numerous beneficial biomolecules which are useful in many applications, for example carbohydrates, essential fatty acids, food supplements, fertilizers, pharmaceuticals, color pigments and biofuels [1,2]. Microalgae are prokaryotic or eukaryotic photosynthetic microorganisms which can grow very rapidly and require only sunlight and water with minimal nutrients. They can adapt to a wide range of growth conditions due to their unicellular or simple multicellular structure. 
Cyanobacteria which are prokaryotic cells are also known as blue-green algae due to their blue-green color brought on by the internal pigment, phycocyanin. Eukaryotic microalgae, on the other hand, are green algae (Chlorophyta) and diatoms (Bacillariophyta) [3]. According to Richmond [4], approximately 50,000 species of algae are in existence, among which, approximately 30,000 have been studied and analyzed. This collection of numerous studied microalgae allows us to explore their use in various applications, such as in the extraction of value-added bioproducts from food crops, carbohydrates, lipids, proteins, pharmaceutical purposes, food for human consumption and various bioenergy products [5]. Depending on the requirements of the products, the algal species, growth conditions, cost, and productivity changes. The availability of water sources (fresh water, basic or alkaline) and nutrients is one of several challenges faced by algaculture. This increases the cost of algae cultivation, which makes the whole process costly. Researchers are focusing on finding new ways to make algae culture cost effective, by maximizing the use of algae mainly in the energy sector and in phycore mediation. It is imperative to realize the synergy between the biodiesel industry, policies and impact of the algae production processes on ecological systems [6].

Microbial fuel cells (MFCs) can be utilized for sustainable bioenergy generation as well as bioelectric synthesis via wastewater treatment processes. MFCs can be fed with the important microalgae culture to generate bioelectricity and increase the efficiency of MFCs. Prior process design integration and the modification of synthetic microbial cells can contribute to the overall process improvement $[7,8]$. For example, various biotechnology start-up industries and research centers have reported sustainable biodiesel production by applying microbial fermentation in a more efficient and cost-effective manner [7]. In addition, algae cultivation integrated with wastewater treatment has much potential in producing algal biofuels at a profitable scale and with sustainable means $[5,9]$.

Life cycle assessment (LCA) is one of the major aspects that needs to be considered in the production of microalgae biomass and products [10]. LCA on the basis of production pathways such as different nutrient sources (wastewater effluent, activated sludge wastewater, manure, and chemical mediums) is crucial. Various biomass conversion technologies such as combustion, microwave pyrolysis, hydrothermal liquefaction and wet lipid extraction need to be compared to identify the cost effectiveness of the overall process. In terms of an economical point of view, wastewater-based biofuels showed higher profitability compared to freshwater-based biofuels as the overall cost of the medium can be greatly reduced. The study on LCA of wastewater-based algal biofuels and its environmental performance on the basis of different production pathways and cultivation as well as conversion methods has already been reported by Mu et al. [11]. This review focuses on the methods and advancements in oleaginous microalgae cultivation for biofuel production. The major products as well as environmental impacts of microalgae cultivation are comprehensively explained, along with potential residual biomass management.

\section{Oleaginous Microalgae and Their Characteristics}

As the name suggests, oleaginous means that which has oily content or which can produce oil. Among thousands of microalgae, some microalgae can produce oily contents, and these microalgae are called oleaginous microalgae. The genus of these algae is Nannochloropsis, comprising six majorly known species. These species generally occur in marine environments but also present in fresh and brackish water. The Nannochloropsis algae contain chlorophyll a, while chlorophyll b and chlorophyll $\mathrm{c}$ are completely absent. The oil from oleaginous microalgae can be used for biodiesel production. In order to maximize the oil content of the oleaginous microalgae, various studies have been carried out by varying growth conditions. It is reported that some strains of Nannochloropsis can accumulate up to $60-70 \%$ of their overall biomass as lipids in nitrogen limitation. Some studies have reported that lipid productivities of some microalgae such as Chlorella sp., Nannochloropsis sp., and Scenedesmus sp. are much higher than those of traditional plantations [12].

The lipid accumulation rate of oleaginous microorganisms characteristically increases under nitrogen-limitation conditions. During nitrogen limitation, algal cells assimilate excess carbon but are 
unable to process cell division, hence the direct conversion of carbon into triacylglycerides (TAGs). Microalgae store TAGs in high concentrations which are mainly used for biodiesel production and hence this is the perfect candidate for a bio-refinery. Under normal growing conditions, algae synthesize the prime component of biological membranes such as membrane lipids, phospholipids, glycerol-phospholipids and glycolipids, etc. On the other hand, under growth-limiting conditions (such as nitrogen starvation), oleaginous algae switch their lipid synthesis pathway to accumulate TAGs. These TAGs cannot be used for synthesizing membranes; hence, they are stored as lipid molecules [13]. In general terms, through the transesterification process, algal oil is converted into biodiesel. Extracted oil from the algae is mixed with alcohol and an acid (or a base), which further produces the fatty acids methyl esters that make up the biodiesel, bioethanol and biomethane.

It is important to develop green products from microalgae with minimum negative environmental impacts of the process to promote the feasibility of these systems. Continuous research is being conducted and efforts are made to commercialize microalgae cultivation and biofuel production at the industrial level in a cost-effective way which are summarized in this review paper in further sections.

\section{Methods of Microalgae Cultivation}

There are several cultivation modes of microalgae, which include the photoautotrophic, photoheterotrophic, mixotrophic and heterotrophic modes. Photoautotrophic microalgae are the most commonly cultivated microalgae and utilizes sunlight as their main energy source and atmospheric $\mathrm{CO}_{2}$ as a carbon source. Nevertheless, other cultivation modes such as mixotrophic and heterotrophic microalgae are known to grow more rapidly with higher cellular oil content as compared to photoautotrophic cells, making them more promising as biofuel feedstock [12,14]. This benefit is compromised though with the higher requirement of organic carbon sources like glucose or acetate for their growth, which leads to an increase in the medium costs by up to 80\% [15]. Fundamental differences between the photoautotrophic, photoheterotrophic, mixotrophic and heterotrophic modes are given in Figure $1[5,16]$.

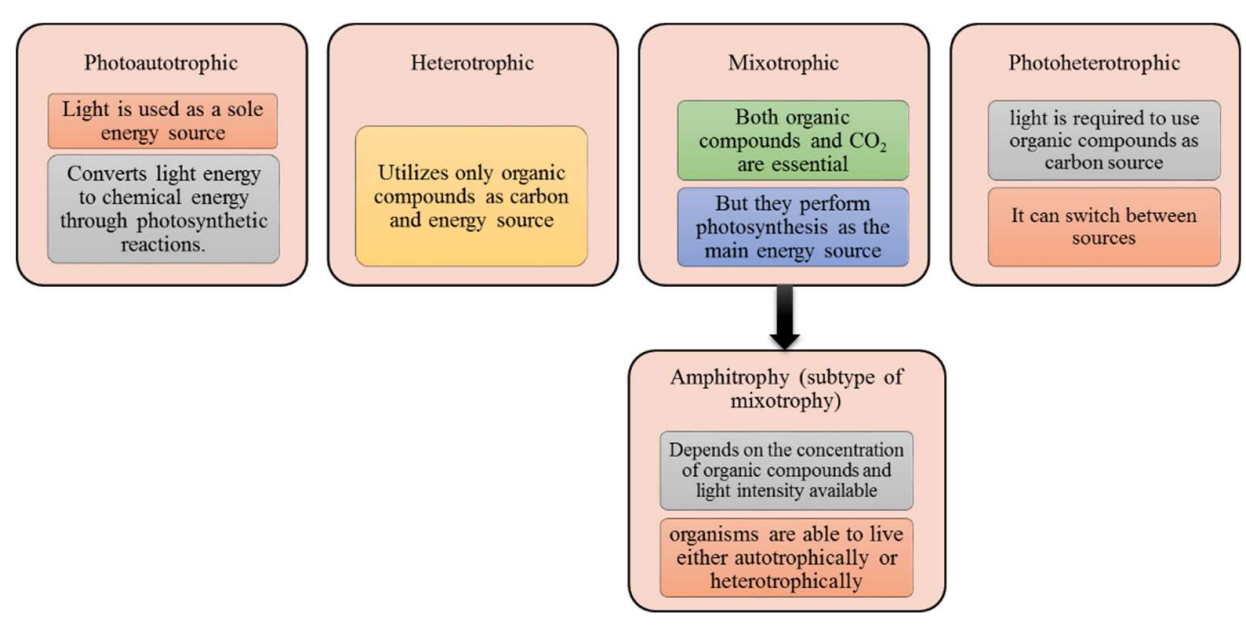

Figure 1. Growth modes of microalgae cultivation on the basis of their metabolism.

Photoautotrophic microalgae are preferably grown in open systems for large-scale cultivation. The advantages of open systems over closed systems are:

(i) The utilization of sunlight and atmospheric air as their surviving source,

(ii) Installation and operating costs are very low,

(iii) Low energy consumption, and

(iv) An external cooling system is not required. 
For the production of highly pure products, axenic cultures in a pure state are required. To grow the pure cultures, closed photobioreactors (PBRs) are preferred over open culture systems. The PBR needs to be designed based on the types of microorganism to be cultivated and the product specifications required. Moreover, high installation and operating costs along with proper and skilled monitoring are necessary. The optimization of parameters for the PBR is a must for proper and efficient function. Proper mixing is often needed in closed systems to prevent the loss of biomass due to the dark zones inside the reactor. On the other hand, in open systems, light penetration is sufficient and can reach around a $20 \mathrm{~cm}$ depth $[5,17,18]$. On the basis of the literature available, some of the major differences in the open and closed systems are highlighted and shown in Figure 2. Another type of cultivation is hybrid cultivation, which is two-stage cultivation that combines different growth stages in PBR and in open pond systems. The first stage of a hybrid system is in a PBR which controls the growth of microalgae and specifies it to the required microorganisms. The second stage involves the exposure of the cells to nutrient stresses in an open pond system to enhance the synthesis of the desired lipid product $[18,19]$.

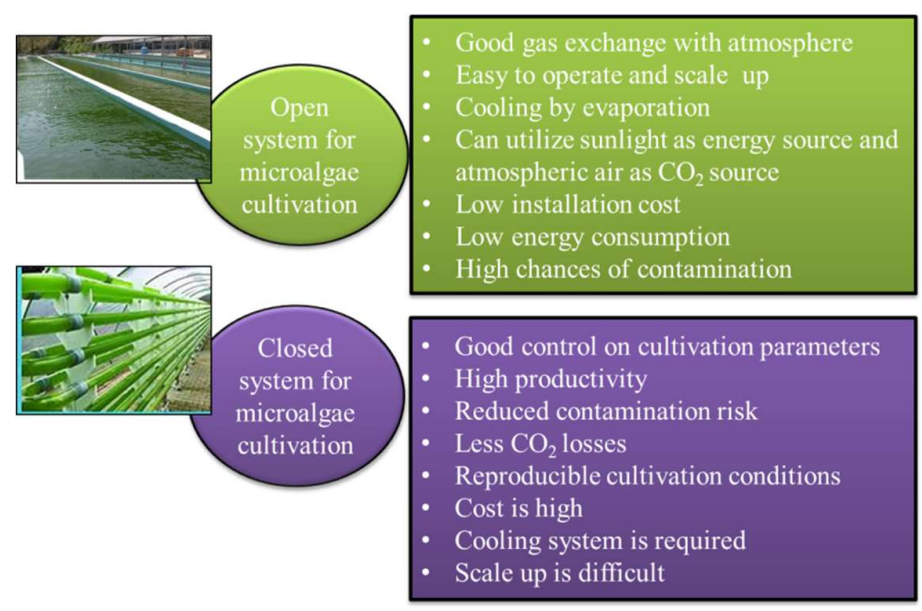

Figure 2. Some of the major differences in the open and closed systems.

Depending on several factors like selected microalgae species, the availability of nutrients and environmental conditions, these parameters affect the algal cultivation operation in either batch or continuous mode. The selection of batch and continuous process also relies on the applicability of microalgae for other purposes like contaminant removal from wastewater, $\mathrm{CO}_{2}$ mitigation, etc. [5]. The correct prediction of the metabolic pathway of the microalgae is necessary to maximize its growth. On the basis of the metabolic pathway, one can select the growth condition of the microalgae as autotrophs, heterotrophs, or mixotrophs. Biomass yield under mixotrophic conditions is higher than that of heterotrophy $[5,12,20]$. Microalgae are adapted to transform their internal structure (biochemical and physiological acclimation) according to the available situations. They can scavenge their environments for storing and utilizing the resources in their maximum efficiency [5].

\section{Advancement in the Cultivation of Oleaginous Microalgae}

The cultivation of microalgae using biofilm in liquid suspension is a prospective method for both open pond and photobioreactor cultivation. However, more research is needed to evaluate the growth characteristics and associated effect factors of the biofilm. Ji et al. [21] reported that the cultivation of oleaginous microalgae species Pseudochlorococcum in an attached biofilm favored accumulating on hydrophilic substrata than on hydrophobic substrata. The light saturation point for the growth was $100 \mathrm{l} . \mathrm{mol} / \mathrm{m}^{2} \mathrm{~s}^{1}$ photon flux density and the optimal inoculum density was found to be approximately 3-5 $\mathrm{g} / \mathrm{m}^{3}$ [21]. 
Bracharz et al. [22] have reported, for the first time, the use of chitosan and tannin (CFL-PT) as an algae flocculant that focuses on harvesting halophilic strains. The cost of the harvesting and dewatering process is significantly high for industrial-scale production. This calls for the need to develop energy efficient techniques that will help to mitigate the energy- and cost-related problems. The flocculation of Scenedesmus obtusiusculus microalgae in a salt-based medium was investigated. CFL-PT was added as algae flocculent and the process was induced by a $\mathrm{pH}$ shift. It was discovered that induction by $\mathrm{pH}$ shift is more cost effective, but a large amount of the base is required to raise the $\mathrm{pH}$ due to the buffering effect of the saline cultivation medium. The tannin appears to be favorable for culturing the microalgae when compared to chitosan in the absence as well as in the presence of algae organic matter (AOM). The cultivation time did noticeably affect the flocculation efficiencies of tannin and other parameters like algae zeta potential and bacterial communities presence remained stable when tannin was used as a flocculant [22].

Possible efforts have been made by Mitra et al. [15] for the production of cheap organic substrates for reducing the microalgae production cost without compromising the nutritional qualities of oleaginous microalgae. The use of cassava starch hydrolysate [23] and corn powder hydrolysate [24] has been reported to be useful as glucose substitutes for improving the lipid yields of microalgae Chlorella protothecoides. Mitra et al. [15] tested two agro-industrial co-products, thin stillage (TS) (waste from dry-grind corn ethanol process) and soy whey (SW), for mixotrophic/heterotrophic microalgae cultivation and compared them with synthetic modified basal medium (MBM) which contains glucose as the carbon source. The heterotrophic growth of Chlorella vulgaris was scaled up to a 61 stirred bioreactor and subjected to ultrasonication and solvent extraction treatments to recover intracellular oil from dried biomass. Dry biomass yields in the bioreactor using thin stillage, soy whey and MBM after 4 days (mixotrophic conditions) were $9.8,6.3$, and $8.0 \mathrm{~g} / \mathrm{L}$, respectively. Depending on the growth media characteristics, the oil content from thin stillage was $43 \%$; from soy whey, it was $11 \%$; and from MBM, it was $27 \%(\mathrm{w} / \mathrm{w})$. Biomass yields in heterotrophic and autotrophic conditions are summarized in Table 1. The oil produced from C. vulgaris grown on both thin stillage and MBM medium contains higher contents of linoleic and linolenic acids.

Table 1. Biomass yields in heterotrophic and mixotrophic conditions [15].

\begin{tabular}{ccc}
\hline \multirow{2}{*}{ Media Used } & \multicolumn{2}{c}{ Biomass Yields (g/L) and Other Properties } \\
\cline { 2 - 3 } & Heterotrophic Conditions & Mixotrophic Conditions \\
\hline Thin stillage & 5.8 & 9.8 \\
\hline Soy whey & 2.5 & 6.3 \\
\hline Modified basal medium & 5.6 & 8.0 \\
\hline Color & Observed Characteristics & \\
\hline Lipid yield & Yellow color & Pale green \\
\hline
\end{tabular}

The higher cell densities under mixotrophic conditions are a result of the combination of photosynthesis and aerobic respiration coupled with the catabolism of carbohydrates present in the medium. It is reported that microalgae gives higher oil productivity in mixotrophic conditions if the availability of carbon is increased, which in turn increases the proportion of storage lipids [25].

The growth of $C$. vulgaris in autotrophic conditions can occur with natural resources (e.g., $\mathrm{CO}_{2}$ and $\mathrm{H}_{2} \mathrm{O}$ ) utilizing the radiant energy from the sun. This process also reduces the global $\mathrm{CO}_{2}$ emission and microalgae can be grown in places where other crops cannot grow due to the extreme water salinity, excessive exposure to sunlight and lack of important nutrients [14]. Culturing microalgae in heterotrophic or mixotrophic conditions instead is cost effective for algal oil production $[13,25]$. Adding both glucose and acetate (both $1 \%, \mathrm{w} / \mathrm{v}$ ) in dark cultivation, the cell growth rates were found to increase 
by approximately 8 -fold in 12 days, where glucose addition produced better growth rates than that of acetate. Biomass and lipid productivities were observed to be low under autotrophic growth conditions when compared with heterotrophic growth, whereas for mixotrophic growth conditions, a lower dose of glucose (1\% and $2 \%)$ improved cell growth significantly while higher doses of glucose $(5 \%$ and $10 \%$ ) inhibited algal growth. Wang et. al., [26] reported the higher growth of oleaginous microalgae in heterotrophic conditions when compared with the photoautotrophic conditions. These results are in accordance with the previously reported studies. For instance, the same phenomenon was observed when 1.5 and $6 \%$ of glucose was fed to the C. protothecoides by Xiong et al. [27]. Biofuels derived from biomass are more sustainable compared to fossil fuels as they cause less water pollution and produce less greenhouse gas emissions. Recent studies are focusing on the extraction of high-value products from microalgae without wasting the byproducts to improve the economics of biorefineries run on the microalgae. Microalgae can be used for the extraction of bioenergy, biofuel, biochemicals compounds and high-value bioproducts such as lipids, proteins, carbohydrates, pigments, antioxidants and vitamins through various processes.

Microalgae can grow under various aquatic environments, which include fresh water, brackish water, marine water and wastewaters. Microalgae can be grown in municipal, industrial, agricultural and domestic wastewaters when present with various suitable nutrients $[28,29]$. The wastewater collected from a secondary wastewater treatment plant has been used to cultivate Scenedesmus obliquus. The single-cell green microalgae were isolated and maintained and grown in a $250 \mathrm{~mL}$ conical flask containing $150 \mathrm{~mL}$ of wastewater (WW) and Bold's Basal Medium (BBM) combinations. The percentages of WW/BBM mixtures investigated were 25:75, 50:50 and 75:25 (only WW or BBM were taken as control). It was depicted from the results that up to $75 \%$ wastewater substitution was helpful in increasing the biomass production of the lipid-rich microalgae for subsequent biodiesel production. This utilization of wastewater also saves water and nutrient consumption by using the nutrients available in the wastewater. The results indicated the suitability of using growth medium and wastewater mixtures for production of algal biomass [29]. In addition, secondary effluents rich in nitrogen and phosphorus which need prior treatment before discharged into receiving water bodies can also be used for the growth of microalgae. The microalgae will absorb high amounts of contaminants in the secondary effluent and simultaneously clean the wastewater sources while accumulating valuable biochemical content [28].

Microalgae can also be immobilized in gel beads to improve the productivity of the biomass. A study by Cheirsilp et al. [30] reported the cultivation of Nannochloropsis sp. immobilized in alginate gel beads. The flow chart of the procedure is given in Figure 3 [30]. The immobilized cells successfully removed over $90 \%$ nitrogen and phosphorus and contributed to over $99 \% \mathrm{CO}_{2}$ mitigation. Biomass produced from the immobilized cells was $1.300 \pm 0.050 \mathrm{~g} / \mathrm{L}$ and the lipid production was $0.356 \pm 0.097 \mathrm{~g} / \mathrm{L}$. The scale up of the process was carried out and comparable lipid production rate was obtained, indicating the suitability of this technique for biodiesel production. The immobilization of microalgae in alginate beads resulted in the tertiary treatment of industrial effluent as well as contributing to $\mathrm{CO}_{2}$ mitigation with the ability to produce low-cost renewable energy [30]. Various studies on the growth media and cultivation systems used for oleaginous microalgae are shown in Table 2 . The advancement in science and engineering should be blended together to produce novel systems that can increase the yield and productivity of microalgae to produce required biomolecules in a more feasible way [22]. 


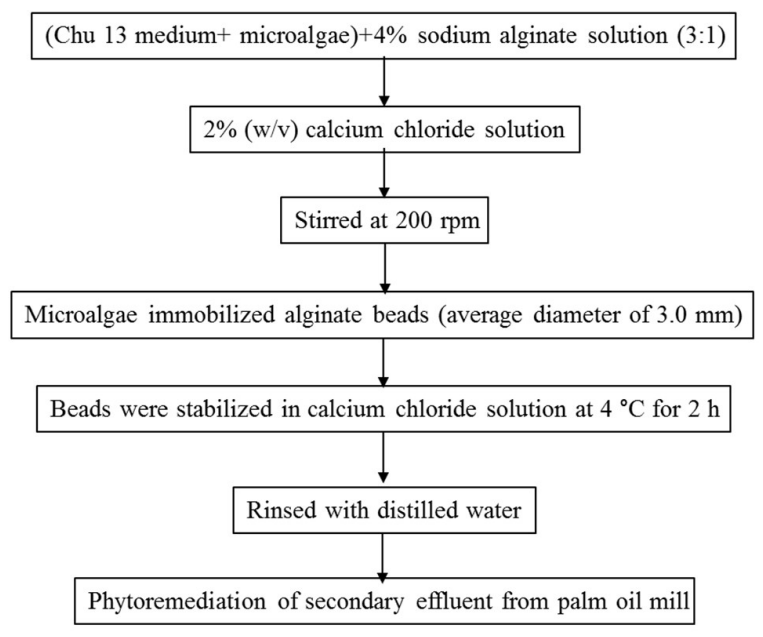

Figure 3. Flow chart of the procedure used for the immobilization of microalgae with alginate beads [30].

Table 2. Growth media and cultivation systems used for oleaginous microalgae.

\begin{tabular}{|c|c|c|c|c|}
\hline Microalgae Used & Media & Culture Systems & $\begin{array}{l}\text { Experimental } \\
\text { Conditions }\end{array}$ & Reference \\
\hline Chlorella vulgaris & $\begin{array}{l}\text { Modified basal medium, soy } \\
\text { whey and thin stillage with } \\
100 \mathrm{mM} \text { buffer strength }\end{array}$ & $\begin{array}{c}\text { Heterotrophic growth, } \\
\text { heterotrophic and mixotrophic } \\
\text { batch cultivation, and mixotrophic } \\
\text { batch cultivation }\end{array}$ & $\begin{array}{c}\mathrm{pH} \text { of media } \\
\text { maintained was } 5 \\
6,6.8,7.5 \text { and } 8 \\
28{ }^{\circ} \mathrm{C} \text { for } 5 \text { days }\end{array}$ & [15] \\
\hline $\begin{array}{l}\text { Scenedesmus } \\
\text { obtusiusculus }\end{array}$ & $\begin{array}{c}\text { Chitosan and tannin (CFL-PT) } \\
\text { as flocculent }\end{array}$ & & Salt-based medium & [22] \\
\hline Chlorella vulgaris & Acetate, glucose, and glycerol & $\begin{array}{l}\text { Autotrophic, heterotrophic and } \\
\text { mixotrophic growth }\end{array}$ & $\begin{array}{l}150 \mathrm{rpm} \text { air flow } \\
\text { rate of } 200 \mathrm{~mL} / \mathrm{min}\end{array}$ & [14] \\
\hline $\begin{array}{l}\text { Scenedesmus } \\
\text { obliquus }\end{array}$ & $\begin{array}{l}\text { Secondary treated municipal } \\
\text { wastewater and Bold's } \\
\text { basal medium }\end{array}$ & $\begin{array}{c}75 \% \text { wastewater }(\mathrm{WW})+25 \% \\
\text { Bold's Basal Medium }(\mathrm{BBM}) \\
100 \% \text { BBM }\end{array}$ & & [29] \\
\hline $\begin{array}{c}\text { Chlorella pyrenoidosa } \\
\text { II-H6 }\end{array}$ & BG11, 13 days & $\begin{array}{c}\text { Atmospheric and room } \\
\text { temperature plasma technique }\end{array}$ & $33^{\circ} \mathrm{C}$ and 9.0 & [31] \\
\hline Nannochloropsis sp. & Chu 13 medium & $\begin{array}{l}\text { Immobilized alginate beads } \\
\text { in PBR }\end{array}$ & $30 \pm 2{ }^{\circ} \mathrm{C}$ for 7 days & [30] \\
\hline Tribonema minus & BG11 medium & Heterotrophic condition & $23 \pm 1^{\circ} \mathrm{C}$ & [26] \\
\hline Scenedesmus sp. & Secondary effluent & Heterotrophic & - & [28] \\
\hline $\begin{array}{l}\text { Scenedesmus } \\
\text { obliquus SIT06 }\end{array}$ & BG11 & Photoautotrophic & $28^{\circ} \mathrm{C}$ for 10 days & [32] \\
\hline
\end{tabular}

Among all the available cultivation processes, mixotrophy is found to be more efficient for the production of algal biomass compared to the phototrophic and heterotrophic cultures [33]. However, research is still ongoing to overcome the limitations of pilot-scale microalgae cultivation in open ponds systems. The challenges present are the organic carbon substrates in the medium and the possibility of heterotrophic bacterial contamination leading to the inefficient conversion of the organic carbon source. Generally, the microalgae which contain lipid contents of over $20 \%$ of the dry weight of the cells are called oleaginous microalgae. It is reported that the average lipid contents of algal cells varies between $1 \%$ and $70 \%$ but, if specific conditions are provided for their growth, it can reach up to $90 \%$ of the dry weight. The lipid content of several oleaginous microalgae are given in Table 3, which indicates that the common lipid content in microalgae is in the range of $20-50 \%[34,35]$. 
Table 3. Some of the oil-producing algae and their oil content. [35].

\begin{tabular}{cc}
\hline Algae & Oil Content (\% Dry Cell Weight) \\
\hline Botryococcus braunii & $25-75$ \\
\hline Chlorella sp. & $28-31$ \\
\hline Dunaliella sp. & 23 \\
\hline Neochloris & $35-54$ \\
\hline Nannochloropsis sp. & $31-68$ \\
\hline Oleoabundans phaeodactylum & $20-30$ \\
\hline
\end{tabular}

Chlorophyta, Bacillariophyceae and Chlorella species of microalgae have better oil contents and they are easy to cultivate for industrial applications. Ample studies have claimed to improve lipid accumulation in microalgae by applying metabolic engineering strategies. This modification approach is classified into five different methodologies which are: (1) overexpression of the enzymes involved in fatty acid biosynthesis pathway; (2) overexpression of enzymes to expand the Triacylglycerol (TAG) biosynthesis pathway; (3) regulation of TAG biosynthesis bypass approaches; (4) partial blockage of competing pathways; (5) multi-gene transgenic approaches [34]. The modifications can be performed by altering growth conditions to provide the best conditions for the selected microalgae.

Studies have reported utilizing wastewater as a growth medium for oleaginous microalgae, which resulted in enhanced lipid contents. Scenedesmus obliquus SIT06 cultivated in 100\% wastewater produced a higher percentage (54.8\%) of C16-C18 fatty acids from total lipids compared to $47.0 \%$ in $100 \%$ of growth medium BBM. The increase in the biomass lipid fraction (C16-C18) when cultivated in wastewater may be due to the starvation condition [29]. Another work on microalgae cultivation on wastewater exhibited good growth and strong anti-contamination capabilities, which helps them to quickly adapt to outdoor conditions for growth. In PBR conditions, over 60\% of the total neutral lipids, with almost $70 \%$ being triacylglycerols, were accumulated predominantly. In addition, Scenedesmus obliquus mainly displayed the contents of monounsaturated fatty acids, whereas oleic acid (C18:1) content was found to be approximately $27.1 \%$. Scenedesmus strains contain mainly palmitic acid (C16:0), hexadecatetraenoic acid (C16:4), stearic acid (C18:0), oleic acid (C18:1), linoleic acid (C18:2), and linolenic acid (C18:3). Among the different types of lipids, neutral lipids are the main source for biodiesel production and Scenedesmus strains in the study showed $64.03 \pm 1.69 \%$ neutral lipids in S. armatus and $61.92 \pm 2.04 \%$ in S. obliquus [36]. The lipid-rich microalgal strain Graesiella sp. WBG-1 was also studied for its growth and lipid production under indoor and outdoor conditions. Graesiella sp. WBG-1 was capable of producing a high amount of lipid in outdoor mass cultivation, which is promising from an industrial point of view. A high lipid content of $33.4 \%$ dry weight was attained by cultivating the microalgae in a $200 \mathrm{~m}^{2}$ raceway pond. The cultivation process also produced a good biomass growth rate $\left(12.03 \mathrm{~g} / \mathrm{m}^{2} / \mathrm{d}\right)$ and high lipid content $(45.23 \%)$ when cultivated in an industrial circular pond PBR. The use of outdoor PBRs for the cultivation process is feasible and cost effective for the autotrophic cultivation of the microalgae strain for biofuel production [37].

To overcome the contamination problem in mixotrophic cultivation, Graesiella sp. WBG-1 was grown in a sequential phototrophic-mixotrophic cultivation (SPMC) method. SPMC resulted in enhancements in algal biomass productivity and also reduced bacterial contamination in open raceway ponds. The strain successfully produced $12.5 \mathrm{~g}$ biomass and $4.1 \mathrm{~g}$ lipid per $\mathrm{m}^{2}$ per day in the SPMC method cultivated using a $1000 \mathrm{~m}^{2}$ raceway pond. Over $50 \%$ increase in yield was achieved compared to phototrophic-only cultivation, where the bacterial number in SPMC was also similar to that in phototrophic cultivations [33]. Tribonema minus cells grown under heterotrophic conditions, on the other hand, showed suppressed lipid accumulation in heterotrophic cultivation. The reduction in lipid content is mainly due to the down-regulation of glycolysis, de novo fatty acids and lipid biosynthesis, and the up-regulation of gluconeogenesis process [26]. 
The membrane-attached growth of Pseudochlorococcum sp. microalgae was studied in eight types of filtration membranes, namely, polypropylene, polytetra fluoroethylene, bonded fiberglass, polyether sulfone, nylon, cellulose nitrate, cellulose acetate, and mixed cellulose. Compressed $\mathrm{CO}_{2}$-enriched air was supplied to the cultivation reactor and agar solid medium was used to provide nutrients to the microalgae culture. The maximum level of lipid and starch obtained from the microalgae cells were $52.2 \%$ and $12.2 \%$ in dry weight, respectively. The presence of a starch compound enabled its usage as a feedstock for the production of fermentable sugar. Compared with the suspension cultivation, attached and controlled biofilm cultivation performs better to obtain the highest productivity of lipid or starch for Pseudochlorococcum sp. cultivation [21].

\subsection{Attached Microalgal Growth System}

Attached microalgae growth systems are purely dependent on the support structure in photobioreactors and the surface of materials. The growth of microalgae occurs in the submerged systems where support structures with the culture media are present in the bioreactor together. This type of microalgae cultivation is considered feasible for the recovery of algae-based products with the reduced cost $[9,21,38]$. The effectiveness of the attached growth system is that the microalgal cells grow in highly packed formation in the form of biofilms within attached systems, which results in the concentrated biomass of 20 times over that of traditional suspended systems [39]. Some of the examples of other attached cultivation systems include a rotating algal biofilm reactor (RABR) [40], parallel plate air lift reactor, and a revolving algal biofilm [39,41]. There are some limitations of these type of systems though, as the oxygen evolving activity and the main organic composition of cells still needs further research to fully understand their effects on the systems.

Johnson and Wen [9] used a rocking shaker to simulate a lotic environment for microalgae cultivation. Various support structures like polystyrene foam, cardboard, polyethylene fabric and loofah sponge were tested for microalgal growth in the attached form. It was concluded that polystyrene foam resulted in the highest biomass yield of $25.65 \mathrm{~g} / \mathrm{m}^{2}$ and fatty acid yield of $2.31 \mathrm{~g} / \mathrm{m}^{2}$ in 10 days growth. The multiple growths (up to 6 months) on the same polystyrene foam showed the durability and repeatability of polystyrene foam as a support system for the attached microalgae growth systems [9].

The RABR cultivation method was created and used for simple biomass harvesting with the help of a cotton sheet as a supporting material [40]. In the system, liquid nutrient media and $\mathrm{CO}_{2}$ was provided from above. It can be further optimized for the experimental system to obtain the maximum biomass and cost reduction. The RABR system also reduced the need for the centrifugation step as algal biomass collected from the system was found to contain similar water content to centrifuged biomass. The RABR system resulted in a biomass yield of $24.57 \pm 3.36 \mathrm{~g} / \mathrm{m}^{2}$ while, it was $1.81 \mathrm{~g} / \mathrm{m}^{2}$ in flat panel bioreactor [40]. Apart from that, Lin-Lan et al. [41] studied Scenedesmus. LX1 using an attached microalgae culture system, i.e., $10 \mathrm{~L}$ suspended-solid phase photobioreactor (ssPBR) (17 batches with different conditions) and compared it with the suspended growth system. It was found that attached microalgae had lower oxygen evolving activity comparing to suspended microalgae. The average protein content of attached microalgae $(50.1 \% \pm 10.1 \%)$ was found to be nearly $30 \%$ higher than that of suspended algae $(36.0 \% \pm 16.1 \%)$ [41]. Due to the different accumulation rate of different biomass, the cultivation time varied. In spite of the expensive instruments, human labor was still required to harvest the biomass from the support structures efficiently and carefully [42].

As the attached growth system is believed to have more suitability, various studies have developed membrane bioreactors. An algal biofilm membrane photobioreactor (BMPBR) was developed by Gao et al. [43] and its productivity was compared with the suspended growth membrane photobioreactor (MPBR). The bioreactor (BMPBR) was used for the growth of Chlorella vulgaris and the treatment of secondary waste effluent. The bioreactor was equipped with solid carriers and a submerged membrane module. The microalgae biomass produced in BMPBR was $0.072 \mathrm{~g} / \mathrm{L} / \mathrm{d}$ while it was 0.05 in the suspended growth MPBR. A total of $72.4 \%$ of the algal growth formed a biofilm in the reactor, 
which resulted in advanced nutrient removal from the secondary effluent effectively. Indeed, BMPBR showed higher algal biomass hence resulted in better nitrogen removal performance than MPBR [43].

\subsection{Cell Pelletization}

Many filamentous fungi have a tendency to aggregate into large pellets in submerged cultures, which traps microalgal cells at the same time. The pellets formed during the growth process can easily be separated by filtration due to their higher density compared to water. Co-pelletization process has been adopted by researchers to increase the lipid yield and biomass of microalgae [32,44]. Srinuanpan et al. developed the method of the photoautotrophic cultivation of oleaginous microalgae and filamentous fungi in a co-pelletization mode. They reported improvements in the lipid yield and cost-effective harvesting process. For harvesting the co-pelletized cells, the spores of fungi were added into the fully grown 10 days-cultured microalgae and the microalgae-fungi pellets were rapidly formed within $24 \mathrm{~h}$ through the co-pelletization process. The lipid content obtained was $40.86 \pm 0.32 \%$ and the highest microbial biomass obtained was $1.99 \pm 0.12 \mathrm{~g} / \mathrm{L}$. It was concluded that the extracted lipids were mainly composed of C16:0, C18:0 and C18:1, which are desired as fuel properties, showing that the microalgae pellets can be used as potential biodiesel feedstock [32]. Similar studies were also reported by Zamalloa et al., where Chlorella vulgaris microalgae and Aspergillus niger fungi were used. Most of the microalgae cells were attached to pellets within $72 \mathrm{~h}$ of cultivation. The effect of the ions present in the water was tested and it was observed that without $\mathrm{Ca}^{2+}$ and $\mathrm{Mg}^{2+}$, the harvest efficiency was over $90 \%$ [44].

Prajapati et al. attempted to optimize the process to obtain the highest yield possible and reduce the cost of microalgae cultivation through the pelletization process. The selected Aspergillus lentulus fungus was grown with Chroococcus sp. microalgae on BG11 medium in alkaline conditions. It was found that the growth was equally good in neutral (7.0) and acidic $\mathrm{pH}$ (5.0). Interestingly, A. lentulus was able to harvest nearly $100 \%$ of the microalgal cells (at $1.58 \mathrm{~g} / \mathrm{L}$ initial algal concentration) within $24 \mathrm{~h}$ [45]. The results of the co-pelletization findings discussed are summarized in the Table 4.

Table 4. Summary of the flocculation efficiency obtained through a fungal-assisted microalgae co-pelletization technique.

\begin{tabular}{|c|c|c|c|c|}
\hline Microalgae & Fungi & Conditions & $\begin{array}{l}\text { Flocculation } \\
\text { Efficiency }\end{array}$ & References \\
\hline Chroococcus sp. & Aspergillus lentulus & $\mathrm{pH} 7.82,150 \mathrm{rpm}$ & $100 \%$ in $24 \mathrm{~h}$ & [45] \\
\hline Chlorella vulgaris & Aspergillus niger & $\mathrm{pH} 7,150 \mathrm{rpm}$ & $96 \%$ in $72 \mathrm{~h}$ & [44] \\
\hline $\begin{array}{l}\text { Scenedesmus obliquus } \\
\text { SIT06 }\end{array}$ & $\begin{array}{c}\text { Cunninghamella echinulata } \\
\text { TPU4652 }\end{array}$ & pH 5.5, 120 rpm & $92.7 \%$ in $24 \mathrm{~h}$ & [32] \\
\hline
\end{tabular}

\section{Major Products Obtained from Oleaginous Microalgae}

The main concern is in the scaling up of the downstream processes available for the production of low-cost biofuels along with the value-added product recovery to generate high revenues [46]. According to the Ryan and Mayfield, land-area requirements for algae cultivation are very low (4\%) than that of other crops (soya (330\%), jatropha (75\%), oil palm $(23 \%)$ ). It is estimated that algae can yield up to 40,000 liters of biofuel per hectare per year, being cultivated on only 30 million hectares of land and is adequate to replace a portion of the 1200 billion liters of petroleum used in the United States [2]. Other products which are obtained from microalgae are antioxidants, such as vitamins C, E, butylated hydroxytoluene, biofuels (biodiesel, biogas, and bioethanol), pigments, proteins, biopolymers, and biofertilizers [1-3]. Primary metabolites such as fatty acids from microalgae have important roles in protecting the cells against oxidative stress. Other metabolic products such as special polysaccharides, glycerol and amino acids from microalgae are high-value products because of their medical properties. In addition to the above-mentioned compounds, microalgae are also used to extract glycoproteins, antifreeze proteins and antibiotics. 
As mentioned earlier, microalgae can also be cultivated in wastewater, which leads to wastewater treatment by removing contaminants present in the wastewater. Choudhary et al. [47] developed a modified algal biofilm reactor (ABR) for assessing the biomass productivity and treatment potential in different wastewaters. A nonwoven spun bond fabric was used as a suitable support for the growth of biofilm and the algae were grown in various mediums such as livestock wastewater, domestic grey water and anaerobically digested slurry. As a result, high lipid (38\%) content was obtained in grey water biomass and high protein (44\%) content was found in the other two mediums. The net energy ratio (NER) of the of the ABR system was found to be $(>1)$, which suggests that it is potentially useful to treat and manage rural wastewaters while simultaneously producing biomethane, biofertilizers and livestock feed supplements [47].

Bioethanol is the most used biofuel in the global market and is produced from biological sources. Due to the increase in the prices of fuel in the 21st century, bioethanol as an alternative fuel has gained interest from many countries [48], where numerous countries are taking steps to promote ethanol as a possible mainstream fuel [49]. The production of bioethanol from microalgae involves the fermentation of sugars from biomass into bioethanol. The subsequent conversion of bioethanol to biodiesel will be through transesterification in the presence of ethanol or methanol as an acyl acceptor and in the presence or absence of a catalyst [35,50]. The biodiesel serves as a promising alternative to petroleum fuel due to its attractive physicochemical properties which are comparable to existing diesel.

Bio-oils, on the other hand, are produced through the pyrolysis of microalgal biomass, which involves an anaerobic heating process occurring at very high temperatures of 200 and $750{ }^{\circ} \mathrm{C}$ without oxidation. Depending on the speed of pyrolysis, the final product will vary. For instance, the fast pyrolysis of biomass will result in the production of bio-oil and biochar, while slow pyrolysis will synthesize pyrolysis gas and biochar $[11,51]$. Bio-gas produced from microalgae can also be used to provide energy to industries and daily activities by households. It has been utilized as clean and renewable fuel for transportation to replace the usage of petroleum fuels. Major types of bio-gas are biohydrogen and biomethane, which are produced through anaerobic fermentation, dark fermentation, photo-fermentation, bio-photolysis or a combination of these processes [49]. The potential bioproducts that can be obtained from microalgae are summarized in Figure 4 categorically $[2,3]$.

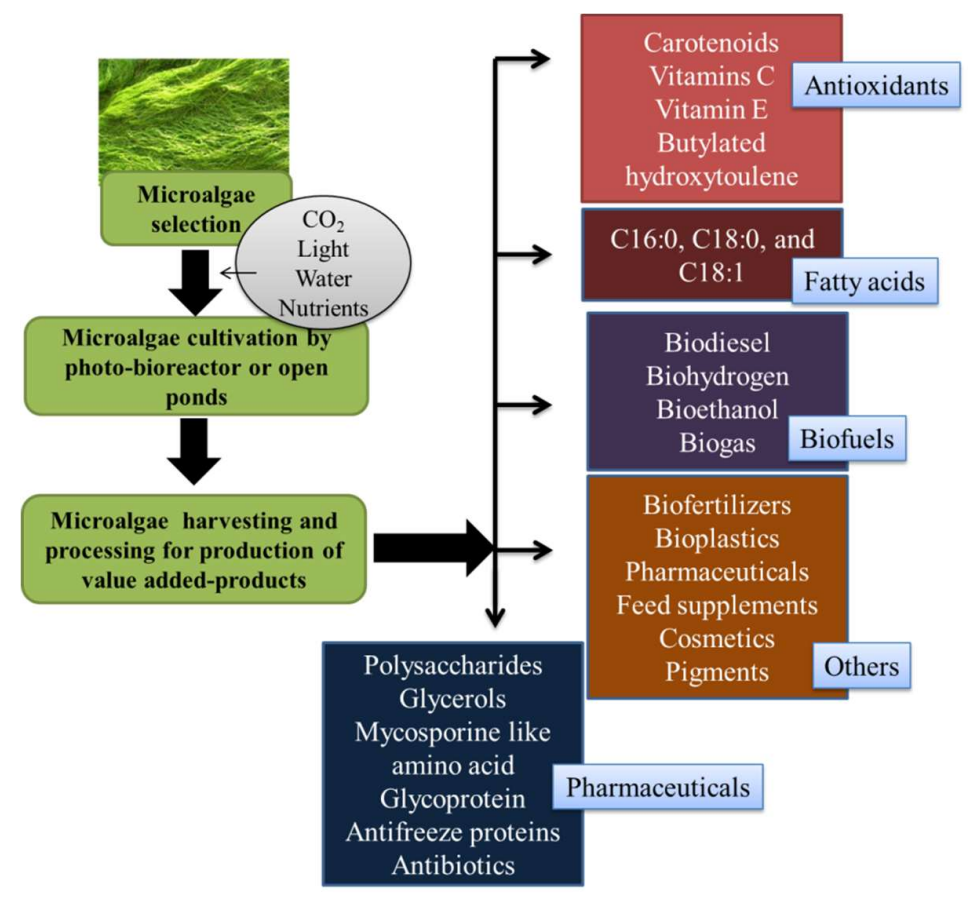

Figure 4. Products obtained from oleaginous microalgae. 


\section{Environmental Impacts of Microalgae}

Productivities of microalgae lipid are much higher than conventional food crops, apart from requiring less cultivation area compared to crops $[2,13,52]$. Although the cost of algal biofuel production is relatively higher than fossil fuels and conventional oils, they are a much-needed option to reduce the environmental impacts caused by the utilization of non-renewable fuels. The cost of biofuel production from microalgae needs to be reviewed and analyzed to reduce the operating as well as capital cost in commercial microalgae cultivation. This can be carried out through integrating water treatment and algal biomass production together in a hybrid system to cultivate the microalgae in mixotrophic conditions [13].

Microalgae generate biomass using photosynthesis to convert sun energy into chemical energy for growth. They have the capability to adopt a variety of environments for growth. For example, they require minimum sunlight, water conditions, and simple nutrients to thrive. This adaptability allows microalgae to be cultivated in local harsh environments which are not suitable for other existing biodiesel feedstocks (palm oil, soybean, sunflower). Conventional fuels also produce a lot of polluting $\mathrm{CO}_{2}, \mathrm{NO}_{2}, \mathrm{~S}$ and various other harmful gases, while algae-derived biodiesel is sulfate-free and contributes to the emission reduction of particulate matter, $\mathrm{CO}$, hydrocarbons, and SOx. The cultivation of microalgae for biofuel production could also contribute to the removal of $\mathrm{CO}_{2}$ from industrial fuel gases by bio-fixation [3]. Moreover, algae cultivation in wastewater sources can aid in reducing the contaminants from wastewater by utilizing $\mathrm{NH}_{4}{ }^{+}, \mathrm{NO}_{3}{ }^{-}$, and $\mathrm{PO}_{4}{ }^{3-}$ as nutrients for microalgae growth $[29,35]$. This procedure could reduce the need for fresh water for the cultivation process and bioremediate wastewater at the same time. Apart from that, the remaining biomass after oil extraction, which is high in N:P ratio, can be further converted to organic amendments or fertilizers. The residue biomass can also be processed into other value-added products such as protein, pigments, natural dyes, antioxidants and carbohydrates for making nutritional supplements or cosmeceuticals products [53].

Algae cultivation for the production of biofuels is advantageous because of its rapid biomass productivity of just a few days. Studies have depicted that algae-based biofuels are more environmentally friendly when compared to fossil fuels but in the aspect of economics, it is not viable for large-scale production with existing technologies [49]. Schneider et al. [10] performed experiments on Desmodesmus subspicatus microalgae biomass in 10 days using an open raceway pond with culture movement by an air-lift system. The algae cultivation was performed using (1) wastewater and (2) Nitrogen-Phosphorus-Potassium (NPK) medium as source of nutrients. Different separation methods were used in both the systems. The LCA model was used to investigate the production of 9 and $12 \mathrm{~kg}$ of microalgae in $8000 \mathrm{~L}$ of wastewater and an NPK solution. Many scenarios were inspected to optimize the environmental impacts of both the methods and nutrient medium used for microalgae biomass production. It was concluded that the scenario configured to using wastewater for microalgae cultivation, followed by processing steps of centrifugation and drying, resulted in the fewest impacts [10].

As reported by Chia et al. [54], the energy produced by microalgal biomass in open pond systems is higher in comparison to the energy consumed by the PBR system. Both the systems can be economically feasible if the NER $<1$. Also, open ponds are said to have lower greenhouse gas (GHG) emissions than PBR systems due to anaerobic digestion of the remaining biomass in open ponds [54].

Sun et al. [55] modelled and compared two types of bioenergy conversion systems on the basis of their NERs and GHG emissions. The two systems are (1) renewable diesel production through transesterification, hydrothermal liquefaction, and pyrolysis (THP) and (2) biogas production through anaerobic digestion with/without hydrothermal pretreatment (AH). Energy consumption was mainly in the processes of fertilizer production and bioenergy conversion ( $>70 \%$ of the total value) in both the processes. The results show that the AH system is more eco-friendly and industrially practical than the former (THP). The NER value for AH was 0.71 and GHG emissions was $-60.84 \mathrm{gCO}_{2} \mathrm{eq}(\mathrm{MJ}$ biogas) ${ }^{-1}$ [55]. 


\section{Residual Biomass Management Which Remains After Lipid Extraction Process}

This is quite obvious that, after every process, there are some residue remains which should be managed for effective and sustainable processes. This section of the paper deals with residual biomass management after the lipid extraction process. It is reported that, apart from biodiesel a microalgae biorefinery can produce various other biofuels such as biohydrogen, biogas, bioethanol, etc. Hemaiswarya et al. [56] reported that microalgal biomass residue after lipid extraction can also be reused for methane production. Microalgae biomass remaining after lipid extraction can also be potentially used as feedstocks in food, feed, pharmaceutical, and cosmetic industries, etc., as shown in Figure 4 [56-58]. There is limited applicability of such processes due to costly processes but the utilization of lipid-extracted microalgae biomass (LEMB) to produce different energy sources along with the extraction of high value-added products will make the microalgal biorefinery approach more inventive and economically plausible. Recently, Mishra and Mohanty [57] reported the comprehensive characterization of lipid-extracted microalgae biomass (LEMB) by biochemical, thermo gravimetric analysis (TGA), Fourier transform infra-red (FTIR), and carbon, hydrogen, nitrogen, sulfur (CHNS) analysis and its utilization for the production of value-added products such as growth promoter, feedstock for biogas, bioethanol, and bio-oil production [57]. According to recent studies, the generated amount of lipid-extracted microalgae biomass is estimated to be thrice the amount of biodiesel produced and it is assumed that microalgal biomass extraction yields $25 \%$ oil [59]. Even after lipid extraction for biodiesel production, LEMB contains a considerable amount of nutrients such as carbohydrates, proteins, nitrate, phosphates, glucose, arabinose, xylose and other micronutrients [58,59]. In order to achieve the zero-waste approach in a microalgae refinery, Mishra and Mohanty [57] have shown that the comprehensive characterization of LEMB derived from wastewater-treated microalgae (wastewater as a growth medium) was found to contain carbon $47.04 \%$, hydrogen $7.29 \%$, nitrogen $6.6 \%$, sulfur $0.16 \%$, and oxygen $38.91 \%$, while the elemental composition of the BG11-derived LEMB contained carbon $50.18 \%$, hydrogen $7.51 \%$, nitrogen $6.3 \%$, sulfur $0.11 \%$, and oxygen $35.9 \%$, respectively. The work concluded that LEMB can be used as a feedstock for bio-oil production by pyrolysis as well as a growth promoter and enhancer [57].

\section{Conclusions and Future Prospective}

Various technologies are involved for the production of biofuels from third-generation feedstock; they include biomass cultivation, dewatering, harvesting, biofuel and bioproduct conversion, biorefinery, nutrient recycling and many more. The sustainable energy potential of oleaginous microorganisms like microalgae is promising and its large-scale production of biodiesel and bioenergy has yet to be implemented globally. Further exploration on the scale up of algae cultivation and processing techniques are needed to establish the potential of algae culture for biofuel production to replace the available non-renewable energy sources. Genetic engineering can also be implemented to improve the metabolic activity of algal cells to maximize the production of the desired biomolecules from microalgae. The focus of research should be on reducing the cost by merging different technologies and developing efficient techniques for biofuel production. This will be a great achievement for the replacement of crude fossil oil with third-generation algae-derived biofuels.

Funding: This work is funded by the Trans Disciplinary Research Grant Scheme (TGRS, TR001-2015A), Universiti Teknologi PETRONAS, YUTP-FRG (0153AA-E48) and Ministry of Education Malaysia under Higher Institution Centre of Excellence (HICoE).

Acknowledgments: The authors would like to acknowledge the Indian Institute of Technology, Kharagpur, India, for providing resources for writing this review paper. We are also thankful to the Ministry of Human Resource Development, India, for providing a fellowship to Preeti Pal.

Conflicts of Interest: The authors declare no conflict of interest. 


\section{References}

1. Chew, K.W.; Yap, J.Y.; Show, P.L.; Suan, N.H.; Juan, J.C.; Ling, T.C.; Lee, D.J.; Chang, J.S. Microalgae biorefinery: High value products perspectives. Bioresour. Technol. 2017, 229, 53-62. [CrossRef] [PubMed]

2. Ryan Georgianna, D.; Mayfield, S.P. Exploiting diversity and synthetic biology for the production of algal biofuels. Nature 2012, 488, 329-335. [CrossRef]

3. Martínez-Francés, E.; Escudero-Oñate, C. Cyanobacteria and microalgae in the production of valuable bioactive compound. In Microlagal Biotechnology; IntechOpen: London, UK, 2018; pp. 105-128.

4. Richmond, A. Handbook of Microalgal Culture: Biotechnology and Applied Phycology; Blackwell Science Ltd.: Hoboken, NJ, USA, 2004.

5. Mata, T.M.; Martins, A.A.; Caetano, N.S. Microalgae for biodiesel production and other applications: A Review. Renew. Sustain. Energy Rev. 2010, 14, 217-232. [CrossRef]

6. Sun, J.; Xiong, X.; Wang, M.; Du, H.; Li, J.; Zhou, D.; Zuo, J. Microalgae biodiesel production in China: A preliminary economic analysis. Renew. Sustain. Energy Rev. 2019, 104, 296-306. [CrossRef]

7. Srivastava, R.K. Bio-Energy production by contribution of effective and suitable microbial system. Mater. Sci. Energy Technol. 2019, 2, 308-318. [CrossRef]

8. Minteer, S.D.; Liaw, B.Y.; Cooney, M.J. Enzyme-Based Biofuel Cells. Curr. Opin. Biotechnol. 2007, 18, $228-234$. [CrossRef] [PubMed]

9. Johnson, M.B.; Wen, Z. Development of an attached microalgal growth system for biofuel production. Appl. Microbiol. Biotechnol. 2010, 85, 525-534. [CrossRef] [PubMed]

10. De Souza Schneider, R.D.C.; de Moura Lima, M.; Hoeltz, M.; de Farias Neves, F.; John, D.K.; de Azevedo, A. Life cycle assessment of microalgae production in a raceway pond with alternative culture media. Algal Res. 2018, 32, 280-292. [CrossRef]

11. Mu, D.; Min, M.; Krohn, B.; Mullins, K.A.; Ruan, R.; Hill, J. Life cycle environmental impacts of wastewater-based algal biofuels. Environ. Sci. Technol. 2014, 48, 11696-11704. [CrossRef]

12. Dong, T.; Knoshaug, E.P.; Pienkos, P.T.; Laurens, L.M.L. Lipid recovery from wet oleaginous microbial biomass for biofuel production: A critical review. Appl. Energy 2016, 177, 879-895. [CrossRef]

13. Yoshida, M.; Tanabe, Y.; Yonezawa, N.; Watanabe, M.M. Energy innovation potential of oleaginous microalgae. Biofuels 2014, 3, 761-781. [CrossRef]

14. Liang, Y.; Sarkany, N.; Cui, Y. Biomass and lipid productivities of Chlorella vulgaris under autotrophic, heterotrophic and mixotrophic growth conditions. Biotechnol. Lett. 2009, 31, 1043-1049. [CrossRef] [PubMed]

15. Mitra, D.; van Leeuwen, J.H.; Lamsal, B. Heterotrophic/mixotrophic cultivation of oleaginous Chlorella vulgaris on industrial co-products. Algal Res. 2012, 1, 40-48. [CrossRef]

16. Perez-Garcia, O.; Bashan, Y. Microalgal Heterotrophic and Mixotrophic Culturing for Bio-Refi Ning: From Metabolic Routes to Techno-Economics. In Algal Biorefineries; Springer: Cham, Switzerland, 2015.

17. Chang, J.; Show, P.; Ling, T.; Chen, C.; Ho, S.; Tan, C.; Nagarajan, D.; Phong, W.N. Photobioreactors. In Current Developments in Biotechnology and Bioengineering; Bioprocesses, Bioreactors and Controls; Elsevier: Oxford, UK, 2017; pp. 313-352.

18. Brennan, L.; Owende, P. Biofuels from microalgae-A review of technologies for production, processing, and extractions of biofuels and co-products. Renew. Sustain. Energy Rev. 2010, 14, 557-577. [CrossRef]

19. Rodolfi, L.; Zittelli, G.C.; Bassi, N.; Padovani, G.; Biondi, N.; Bonini, G.; Tredici, M.R. Microalgae for oil: Strain selection, induction of lipid synthesis and outdoor mass cultivation in a low-cost photobioreactor. Biotechnol. Bioeng. 2009, 102, 100-112. [CrossRef] [PubMed]

20. Tibocha-Bonilla, J.D.; Zuñiga, C.; Silva, R.D.G.; Zengler, K. Biotechnology for biofuels advances in metabolic modeling of oleaginous microalgae. Biotechnol. Biofuels 2018, 11, 1-15. [CrossRef] [PubMed]

21. Ji, B.; Zhang, W.; Zhang, N.; Wang, J.; Lutzu, G.A.; Liu, T. Biofilm cultivation of the oleaginous microalgae. Bioprocess Biosyst. Eng. 2014, 37, 1369-1375. [CrossRef] [PubMed]

22. Bracharz, F.; Helmdach, D.; Aschenbrenner, I.; Funck, N.; Wibberg, D.; Winkler, A.; Bohnen, F.; Kalinowski, J.; Mehlmer, N.; Bruck, T. Harvest of the oleaginous microalgae Scenedesmus obtusiusculus by flocculation from culture based on natural water sources. Front. Bioeng. Biotechnol. 2018, 6, 200. [CrossRef]

23. Wei, A.; Zhang, X.; Wei, D.; Chen, G.; Wu, Q.; Yang, S.T. Effects of cassava starch hydrolysate on cell growth and lipid accumulation of the heterotrophic microalgae Chlorella protothecoides. J. Ind. Microbiol. Biotechnol. 2009, 36, 1383-1389. [CrossRef] [PubMed] 
24. Xu, H.; Miao, X.; Wu, Q. High quality biodiesel production from a microalga Chlorella protothecoides by heterotrophic growth in fermenters. J. Biotechnol. 2006, 126, 499-507. [CrossRef]

25. Chew, K.W.; Chia, S.R.; Show, P.L.; Yap, Y.J.; Ling, T.C.; Chang, J.S. Effects of water culture medium, cultivation systems and growth modes for microalgae cultivation: A review. J. Taiwan Inst. Chem. Eng. 2018, 91, 332-344. [CrossRef]

26. Wang, H.; Zhang, Y.; Zhou, W.; Noppol, L.; Liu, T. Mechanism and enhancement of lipid accumulation in filamentous oleaginous microalgae Tribonema minus under heterotrophic condition. Biotechnol. Biofuels 2018, 11, 328. [CrossRef] [PubMed]

27. Xiong, W.; Li, X.; Xiang, J.; Wu, Q. High-density fermentation of microalga Chlorella protothecoides in bioreactor for microbio-diesel production. Appl. Microbiol. Biotechnol. 2008, 78, 29-36. [CrossRef] [PubMed]

28. Lv, J.; Feng, J.; Liu, Q.; Xie, S. Microalgal cultivation in secondary effluent: Recent developments and future Work. Int. J. Mol. Sci. 2017, 18, 79. [CrossRef] [PubMed]

29. Eida, M.F.; Darwesh, O.M.; Matter, I.A. Cultivation of oleaginous microalgae Scenedesmus obliquus on secondary treated municipal wastewater as growth medium for biodiesel production. J. Ecol. Eng. 2018, 19, 38-51. [CrossRef]

30. Cheirsilp, B.; Thawechai, T.; Prasertsan, P. Immobilized oleaginous microalgae for production of lipid and phytoremediation of secondary effluent from palm oil mill in fluidized bed photobioreactor. Bioresour. Technol. 2017, 241, 787-794. [CrossRef]

31. Cao, S.; Zhou, X.; Jin, W.; Wang, F.; Tu, R.; Han, S.; Chen, H.; Chen, C.; Xie, G.J.; Ma, F. Improving of lipid productivity of the oleaginous microalgae Chlorella pyrenoidosa via atmospheric and room temperature plasma (ARTP). Bioresour. Technol. 2017, 244, 1400-1406. [CrossRef]

32. Srinuanpan, S.; Cheirsilp, B.; Prasertsan, P.; Kato, Y. Photoautotrophic cultivation of oleaginous microalgae and co-pelletization with filamentous fungi for cost-effective harvesting process and improved lipid yield. Aquac. Int. 2018, 26, 1493-1509. [CrossRef]

33. Wen, X.; Tao, H.; Peng, X.; Wang, Z.; Ding, Y.; Xu, Y.; Liang, L.; Du, K. Biotechnology for biofuels sequential phototrophic-mixotrophic cultivation of oleaginous microalga Graesiella sp. WBG-1 in a $1000 \mathrm{~m}^{2}$ open raceway pond. Biotechnol. Biofuels 2019, 2019, 12-27.

34. Liang, M.H.; Jiang, J.G. Advancing oleaginous microorganisms to produce lipid via metabolic engineering technology. Prog. Lipid Res. 2013, 52, 395-408. [CrossRef]

35. Chisti, Y. Biodiesel from microalgae. Biotechnol. Adv. 2007, 25, 294-306. [CrossRef] [PubMed]

36. Sun, Z.; Fang, X. Oleaginous microalgae from dairy farm wastewater for biodiesel production: Isolation, characterization and mass cultivation. Appl. Biochem. Biotechnol. 2018, 184, 524-537. [CrossRef] [PubMed]

37. Wen, X.; Du, K.; Wang, Z.; Peng, X.; Luo, L.; Tao, H.; Xu, Y.; Zhang, D.; Geng, Y.; Li, Y. Effective cultivation of microalgae for biofuel production: A pilot-scale evaluation of a novel oleaginous microalga Graesiella Sp. WBG-1. Biotechnol. Biofuels 2016, 9, 123. [CrossRef] [PubMed]

38. Wilkie, A.C.; Mulbry, W.W. Recovery of dairy manure nutrients by benthic freshwater algae. Bioresour. Technol. 2002, 84, 81-91. [CrossRef]

39. Wang, J.; Liu, W.; Liu, T. Biofilm based attached cultivation technology for microalgal biorefineries-A Review. Bioresour. Technol. 2017, 244, 1245-1253. [CrossRef] [PubMed]

40. Gross, M.; Henry, W.; Michael, C.; Wen, Z. Development of a rotating algal biofilm growth system for attached microalgae growth with in situ biomass harvest. Bioresour. Technol. 2013, 150, 195-201. [CrossRef] [PubMed]

41. Lin-Lan, Z.; Jing-Han, W.; Hong-Ying, H. Differences between attached and suspended microalgal cells in SSPBR from the perspective of physiological properties. J. Photochem. Photobiol. B Biol. 2018, 181, 164-169. [CrossRef]

42. Tan, C.H.; Show, P.L.; Chang, J.S.; Ling, T.C.; Lan, J.C.W. Novel approaches of producing bioenergies from microalgae: A Recent Review. Biotechnol. Adv. 2015, 33, 1219-1227. [CrossRef]

43. Gao, F.; Yang, Z.-H.; Li, C.; Zeng, G.-M.; Ma, D.-H.; Zhou, L. A novel algal biofilm membrane photobioreactor for attached microalgae growth and nutrients removal from secondary effluent. Bioresour. Technol. 2015, 179, 8-12. [CrossRef]

44. Zamalloa, C.; Gultom, S.O.; Rajendran, A.; Hu, B. Ionic effects on microalgae harvest via microalgae-fungi co-pelletization. Biocatal. Agric. Biotechnol. 2017, 9, 145-155. [CrossRef]

45. Prajapati, S.K.; Kumar, P.; Malik, A.; Choudhary, P. Exploring pellet forming filamentous fungi as tool for harvesting non-flocculating unicellular microalgae. Bioenergy Res. 2014, 7, 1430-1440. [CrossRef] 
46. Chia, S.R.; Chew, K.W.; Show, P.L.; Yap, Y.J.; Ong, H.C.; Ling, T.C.; Chang, J.S. Analysis of economic and environmental aspects of microalgae biorefinery for biofuels Production: A review. Biotechnol. J. 2018, 13, e1700618. [CrossRef]

47. Choudhary, P.; Prajapati, S.K.; Kumar, P.; Malik, A.; Pant, K.K. Development and performance evaluation of an algal biofilm reactor for treatment of multiple wastewaters and characterization of biomass for diverse applications. Bioresour. Technol. 2017, 224, 276-284. [CrossRef] [PubMed]

48. Arnold, M.; Tainter, J.A.; Strumsky, D. Productivity of innovation in biofuel technologies. Energy Policy 2019, 124, 54-62. [CrossRef]

49. Chia, S.R.; Ong, H.C.; Chew, K.W.; Show, P.L.; Phang, S.M.; Ling, T.C.; Nagarajan, D.; Lee, D.J.; Chang, J.S. Sustainable approaches for algae utilisation in bioenergy production. Renew. Energy 2018, 129, 838-852. [CrossRef]

50. Suali, E.; Sarbatly, R. Conversion of microalgae to biofuel. Renew. Sustain. Energy Rev. 2012, 16, $4316-4342$. [CrossRef]

51. Bharathiraja, B.; Chakravarthy, M.; Kumar, R.R.; Yuvaraj, D.; Jayamuthunagai, J.; Kumar, R.P.; Palani, S. Biodiesel production using chemical and biological methods-A review of process, Catalyst, Acyl Acceptor, Source and Process Variables. Renew. Sustain. Energy Rev. 2014, 38, 368-382. [CrossRef]

52. Morales, M.; Collet, P.; Lardon, L.; Hélias, A.; Steyer, J.-P.; Bernard, O. Life-cycle assessment of microalgal-based biofuel. Biofuels Algae 2019, 507-550. [CrossRef]

53. Patel, A.; Matsakas, L.; Hrůzová, K.; Rova, U.; Christakopoulos, P. Biosynthesis of nutraceutical fatty acids by the oleaginous marine microalgae Phaeodactylum tricornutum utilizing hydrolysates from organosolv-pretreated birch and spruce biomass. Mar. Drugs 2019, 17, 119. [CrossRef] [PubMed]

54. Correa, D.F.; Beyer, H.L.; Fargione, J.E.; Hill, J.D.; Possingham, H.P.; Thomas-Hall, S.R.; Schenk, P.M. Towards the implementation of sustainable biofuel production systems. Renew. Sustain. Energy Rev. 2019, 107, 250-263. [CrossRef]

55. Sun, C.-H.; Fu, Q.; Liao, Q.; Xia, A.; Huang, Y.; Zhu, X.; Reungsang, A.; Chang, H.-X. Life-cycle assessment of biofuel production from microalgae via various bioenergy conversion systems. Energy 2019, 171, 1033-1045. [CrossRef]

56. Hemaiswarya, S.; Raja, R.; Carvalho, I.S.; Ravikumar, R.; Zambare, V.; Barh, D. An Indian scenario on renewable and sustainable energy sources with emphasis on algae. Appl. Microbiol. Biotechnol. 2012, 96, 1125-1135. [CrossRef] [PubMed]

57. Mishra, S.; Mohanty, K. Comprehensive characterization of microalgal isolates and lipid-extracted biomass as zero-waste bioenergy feedstock: An integrated bioremediation and biorefinery approach. Bioresour. Technol. 2019, 273, 177-184. [CrossRef] [PubMed]

58. Abomohra, A.E.F.; Eladel, H.; El-Esawi, M.; Wang, S.; Wang, Q.; He, Z.; Feng, Y.; Shang, H.; Hanelt, D. Effect of lipid-free microalgal biomass and waste glycerol on growth and lipid production of Scenedesmus obliquus: Innovative waste recycling for extraordinary lipid production. Bioresour. Technol. 2018, 249, 992-999. [CrossRef] [PubMed]

59. Maurya, R.; Paliwal, C.; Chokshi, K.; Pancha, I.; Ghosh, T.; Satpati, G.G.; Pal, R.; Ghosh, A.; Mishra, S. Hydrolysate of lipid extracted microalgal biomass residue: An algal growth promoter and enhancer. Bioresour. Technol. 2016, 207, 197-204. [CrossRef] [PubMed]

(C) 2019 by the authors. Licensee MDPI, Basel, Switzerland. This article is an open access article distributed under the terms and conditions of the Creative Commons Attribution (CC BY) license (http://creativecommons.org/licenses/by/4.0/). 